\title{
The progress of CAR-T therapy in cancer and beyond
}

\author{
Yehong HUANG, Lulu LI, Wenzhuo LIU, Tao TANG, Liming CHEN ${ }^{*}$ \\ Department of Biochemistry, School of Life Sciences, Nanjing Normal University, Nanjing 210023, China. \\ *Correspondence: chenliming1981@njnu.edu.cn \\ https://doi.org/10.37175/stemedicine.v1i3.47
}

\begin{abstract}
Chimeric antigen receptor T (CAR-T) technology is the pinnacle of modern immunology, system biology, synthetic biology and cellular engineering. It is the powerful new player of cancer therapy since the concept of adoptive cell therapy. Clinical success of CAR-T cells targeting antigen unique to $\mathrm{B}$ cell leukemia has made it the focus of new development in cancer therapy. The latest success is reported in a clinical case of using CAR-T cells to treat pediatric acute lymphoblastic leukemia. However, the major challenges are to make CAR-T cells a reliable, controllable, safe and effective platform that could apply to diverse cancer types including solid tumors. In this review we summarize the recent research progress to tackle the challenges and discuss the broader application of CAR-T cells beyond cancer in the context of genome editing era.
\end{abstract}

Keywords: Chimeric antigen receptor $\cdot$ Cancer $\cdot$ Cell therapy $\cdot$ Immunology

\section{Introduction}

Since the "War on Cancer" was launched by US President Richard Nixon in 1971, at the time when human had successfully landed on the moon, however, people are frustrated to see the uprising of cancer incidences worldwide and cancer still remains the top mortality cause in the world (1). The doubt looms in the minds of people whether we could ever win the war. Fortunately, we become so confident in recent years with the advance of new technologies. We have seen the booming of immunotherapy for cancer since it was named the number one breakthrough of the year in 2013 by Science journal (2). The success of immunotherapy in clinics has won the scientists behind the discovery the Nobel Prize in 2018. A new technology of immunotherapy: chimeric antigen receptor $\mathrm{T}$ cell (CAR-T) therapy was awarded the Advance of the Year 2018 by the American Society of Clinical Oncology. It holds the hope for the final resolution for cancer, the grail therapy. The latest success of using CAR-T technology to combat cancer was reported in a clinical case in Singapore to treat acute lymphoblastic leukemia after the chemotherapy and stem cell transplant failed to deliver the outcome $(3,4)$. No

Received: Apr 20, 2020; Accepted: May 31, 2020

(c) The Author(s). 2020 This is an Open Access article distributed under the terms of the Creative Commons License (http://creativecommons.org/licenses/by/4.0/) which permits unrestricted use, distribution, and reproduction in any medium or format, provided the original work is properly cited. doubt it will be the star of Cancer Moonshot task force. In this article, we will briefly introduce the background, the progress and the challenges of CAR-T cell therapy.

\section{CAR-T cell therapy: the next generation of medicine}

Modern medicine was for a long time the extract of natural product or small chemical compound obtained by chemical synthesis. The key technology is analytical and synthetic chemistry. They still remain the mainstay of drugs today and the first pillar of modern medicine. With the development of molecular biology and bioengineering, recombinant proteins or macromolecules became the second pillar of medicine, with Genentech as the herald and model of biotech pharma. Recombinant bio-products like insulin and monoclonal antibodies stand for a substantial proportion of drug market. Now we have the third pillar of medicine, cell therapies like CAR-T cells which have been approved by the Food and Drug Administration (FDA) to treat certain leukemia (5). The therapeutic capabilities of cell entities are distinct. So far, they are the first kind of "live" medicine, which possess unique traits never seen in previous types of medicine. They can grow, proliferate, and move actively towards the drug target. They serve as a platform to equip with multiple armors to tackle the tumor cells and escape the suppressive control of microenvironment (6). They are complex system and subject to manipulation by the theory of control through positive or negative feedback mechanism. The design and manufacture of these agent are 
totally different from previous generations of drugs and are more challenging. The foundation comprises of cellular system and synthetic biology, gene transfer technique, monoclonal antibody technology, cell engineering method, and the latest genome editing toolkits. Nonetheless, the corner stone for CAR-T therapy is the deep understanding of immunology and the concept of immunotherapy of cancer.

\section{The foundation of immunotherapy}

Immune checkpoint therapy and cell-based therapy like CAR-T are all dependent on the function of immune system: to recognize the danger and clear the threat, either from the outside world or inside the cells of the organism. Immune system in mammals comprises the innate and adaptive branches of immunity. Innate immunity is found in most animals and plants, it is responsible for the firstline defense of pathogens through pattern recognition of different types of foreign molecules, which is usually nonspecific and antigen-independent (7). Adaptive immunity is only found in vertebrates and it has evolved to provide delicately regulated repertoire of recognition for both self and non-self antigens through complex network between different cell types, especially between antigen-presenting cells (APC) and T/B lymphocytes which involve the formation of immunological synapse consisting of $\mathrm{B}$ or $\mathrm{T}$ cell receptors (BCR or TCR) and their cognate ligand with antigen and co-stimulatory molecules. The recognition of different antigens in specific circumstances leads to pathogen-specific effector $T$ cell activation and elimination of pathogens or diseased cells, generation of memory $\mathrm{T}$ or B cells, or immune tolerance of self-antigen, collectively regulating the homeostasis of the immune system (8).

Before we introduce the structure of chimeric antigen receptor, we first briefly talk about the natural TCR. The TCR is normally a heterodimer composed of two different subunits selected from the four different types of polypeptides: $\alpha, \beta, \gamma, \delta$ (Figure 1). In human T cells, $95 \%$ of the TCR consists of an $\alpha$ and $\beta$ chain, the rest $5 \%$ TCR is composed by $\gamma$ and $\delta$ chains. TCR is a member of immunoglobulin superfamily and resembles the structure of a half antibody (light chain and heavy chain without the Fc region). The TCR module is like an antibody anchored on $\mathrm{T}$ cell membrane and responsible for recognizing antigens which are presented by major histocompatibility complex (MHC) molecules on the surface of APCs or tumor cells. However, it has no signaling function on its own as its cytoplasmic tail is very short. The TCR heterodimer then forms a complex with Cluster of Differentiation (CD) 3 and $\zeta$ chain which can transduce the signal into different pathways such as nuclear factor kappa B (NFкB), phosphoinositide 3-kinase (PI3K), mitogen activated protein kinase (MAPK) through recruitment of tyrosine kinases lymphocyte-specific protein tyrosine kinase (Lck), tyrosine protein kinase Fyn, zeta-chain associated protein kinase 70 (Zap70), subsequently promoting the proliferation and differentiation of cells (9). The TCR complex also recruits or interacts with co-receptors like CD4, CD8, and co-stimulatory

\section{TCR}

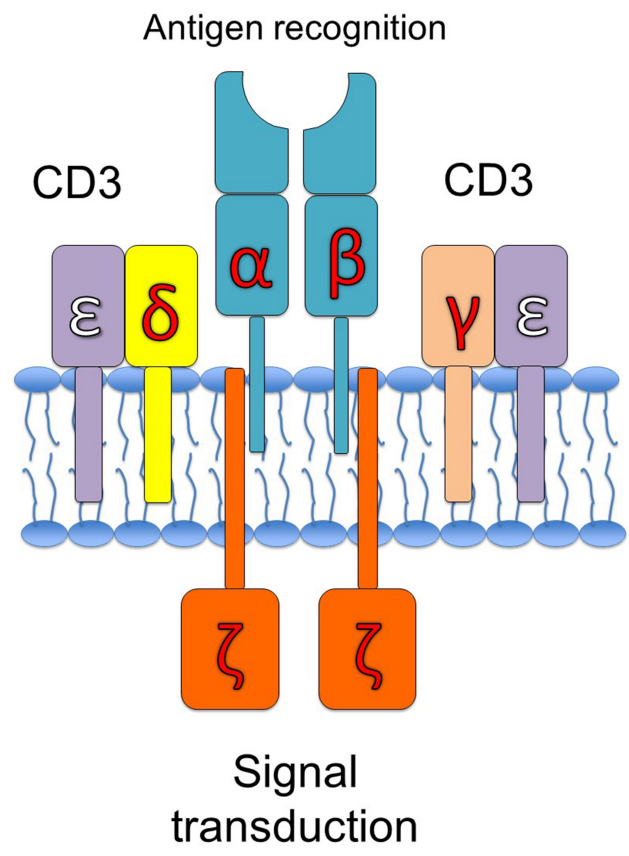

Figure 1. The diagram of TCR structure.

molecules CD28, Inducible T-cell COStimulator (ICOS), OX40, and 4-1BB for optimal activation upon MHC engagement. Upon binding of its ligands CD80/CD86, CD28 is activated and helps amplifying the TCR signaling which turns on cytokine production, cell cycle progression and metabolism reprogramming. 4-1BB belongs to TNFR superfamily and can be induced by TCR and CD28 signaling in both CD4+ and CD8+ cells (10). When engaged with 4-1BB ligand, 4-1BB transduces signal to enhance $\mathrm{T}$ cell proliferation, cytokine secretion and cytolytic potential, and more importantly, to reduce the sensitivity of cells to inhibition by transforming growth factor- $\beta$ (TGF $\beta)$ (11). T cells are also under negative regulation of inhibitory molecules like Programmed cell death 1 (PD1), Cytotoxic T lymphocyte antigen-4 (CTLA-4), Lymphocyte activation gene 3 (LAG3) and T cell immunoglobulin-3 (TIM-3) which are the targets of immune check point therapy (12).

Many different subtypes of $\mathrm{T}$ cells are identified to distinguish their diverse functions in immune response: CD8+ cytotoxic $\mathrm{T}$ cell, CD4+ $\mathrm{T}$ helper cells, memory $\mathrm{T}$ cells, regulatory $\mathrm{T}$ cells, and innate-like $\mathrm{T}$ cells including natural kill $\mathrm{T}$ cells and gamma delta $\mathrm{T}$ cells (13-15). Once activated, cytotoxic $\mathrm{T}$ cells are found to have the direct killing ability to eliminate cancer cells, infected or damaged cells by releasing cytotoxins perforin, granzymes and granulysin, or through FAS ligand mediated apoptosis. The targeting of cytotoxic $\mathrm{T}$ cells was tightly regulated by MHC-I complex with antigen presented by APCs or tumor cells. This unique trait makes it a potential therapeutic agent for cancers (16). 


\section{The hint from adoptive cell therapy}

More than a century ago, pioneer immunologist Paul Ehrlich has proposed the term of "magic bullet" which means to harness the power of immune system for disease intervention (17). His scientific achievements won him the Nobel Prize in 1908. The bullet is to specifically target diseased tissue/cells and leave healthy tissue intact. With scientific breakthrough in the biomedical field, people have seen antibiotics, antibodies and targeted small chemical compounds as the examples of magic bullets at different stages. Now we have the latest version, CAR-T cells, also the most advanced generation.

The use of $\mathrm{T}$ cells in cancer treatment, adoptive cell therapy, can trace back to more than 20 years ago, when non-genetically modified $\mathrm{T}$ cells were expanded in exvivo and infused back to melanoma patients to show good safety and achieve objective tumor regression in $50 \%$ of the patients $(18,19)$. Similar treatment was used on infectious disease such as CMV and HIV virus infected patients $(20,21)$. Autologous tumor-infiltrating lymphocytes (TILs) are the most effective source of adoptive cell treatment so far. However, there are several limitations for this therapy. Firstly, the isolation and preparation of this kind of TIL are labor-intensive and complex. Secondly, activation of these TILs is dependent on the native TCR and optimal engagement with MHC matching to each patient, which is a daunting task given the enormous pool of MHC alleles. Thirdly, the affinity between TCR and tumor antigen is roughly low, in micromolar range, compared to the high affinity between viral peptide and TCR at nanomolar range. This will likely limit the recognition and antigen-specific activation of cytotoxic $\mathrm{T}$ cells.

To overcome the limitations of endogenous TILs used in adoptive cell therapy, researchers developed the chimeric antigen receptor $\mathrm{T}$ cells.

\section{The concept of CAR-T design and evolution}

In a word, the design of CAR-T is following the principles governing the behaviors of endogenous $\mathrm{T}$ cell in the body. Firstly, T cells need to move towards the target via the leukocyte trafficking system. They are mobilized by chemokine signaling and leukocyte recruitment pathway. Secondly, they can recognize the target. The recognition of antigen is assisted by APC via processing of antigen peptides and presenting on the surface by the MHC complex. It has super flexibility and enormous potential rendered by TCR rearrangement and $\mathrm{MHC}$ diversity. This is critical for the organism to respond to numerous antigens in a well-controlled manner. However, the delicate system is highly prone to being hijacked by tumors and becomes a weakness for immune defense. Thirdly, T cells need to be activated and able to proliferate under tight control to avoid the self-damage of normal tissues. When the threat is cleared, T cells need to return to dormant or inactive state, but possess the ability to revive when the old threat is detected again. Lastly, T cells need to survive in or overcome the suppressive tumor environment, which is frequently associated with inert of
$\mathrm{T}$ cells seen in various cancers especially in solid tumors.

The key innovation of CAR-T cells is to replace the variable region of TCR heterodimer with the counterpart from another antibody, both of which are responsible for antigen recognition and are structurally similar. The concept that CAR could recognize target independent of the MHC complex and co-stimulation signal was successfully validated in late 1980 s by Kuwana and Eshhar group $(22,23)$. Another key innovation is to simplify intracellular signaling domain into a single chain receptor comprising of CD8 extracellular and transmembrane domain and $\mathrm{CD} 3 \zeta$ cytoplasmic domain. The chimeric receptor can express independently of TCR and transduce signal like the native TCR complex (24). These scientific innovations paved the road for the application of CAR-T cells in clinics. It takes more than 20 years from basic concept to actual clinical approval.

In the first-generation CAR-T cells, the sensor domain of conventional TCR was replaced by a single chain variable fragment $(\mathrm{scFv})$ which mimicked the antigen recognition structure of anti-CD19 antibody (Figure 2). This design significantly reduced the complexity of heterodimer TCR chains and it enabled the convenient expansion to various targets by switching the scFv module to desired antigen binding domain. Target selection is key to the success of CAR-T and will be discussed further in the later section. Then the extracellular antigen binding domain was fused through a hinge and transmembrane domain with intracellular signaling module $\mathrm{CD} 3 \zeta$ chain. In this way a single chain chimeric receptor could execute the core functions of the native TCR complex composed of more than eight subunits, even in the absence of the MHC complex. This is a great leap of progress in the design of CAR.

To enhance the activation of CAR-T cells, a costimulatory domain from CD28 or $4-1 \mathrm{BB}$ was inserted between transmembrane domain and the TCR signaling motif CD3 $\zeta$ domain. This is the design of the secondgeneration CAR (Figure 2). There was some difference between CD28 and 4-1BB-based CAR co-stimulation effect: CD28-based CAR showed enhanced proliferation and effector functions, while 4-1BB-based CAR induced more pronounced progressive $T$ cell accumulation which may compensate for less immediate potency (11). Other co-stimulation domains from CD27, OX40, ICOS and RIAD were also tested in various settings.

The first FDA approved CAR-T therapy Kymriah is the third generation of CAR-T therapy. The upgrade from the second generation is to insert both CD28 and 4-1BB costimulatory domains in tandem before the CD3 $\zeta$ domain, which will further enhance the activation of T cells (Figure 2). Moreover, this combination of co-stimulatory domains can boost the efficacy of CAR with low binding affinity, expanding the choice of antigen recognition motifs (25). There was also different combination of co-stimulation domains like CD28 plus OX40 in the third generation CAR-T which showed largely similar functionality and persistence. However, some unique trait was found in CAR-T with different combinations. In a neuroblastoma 


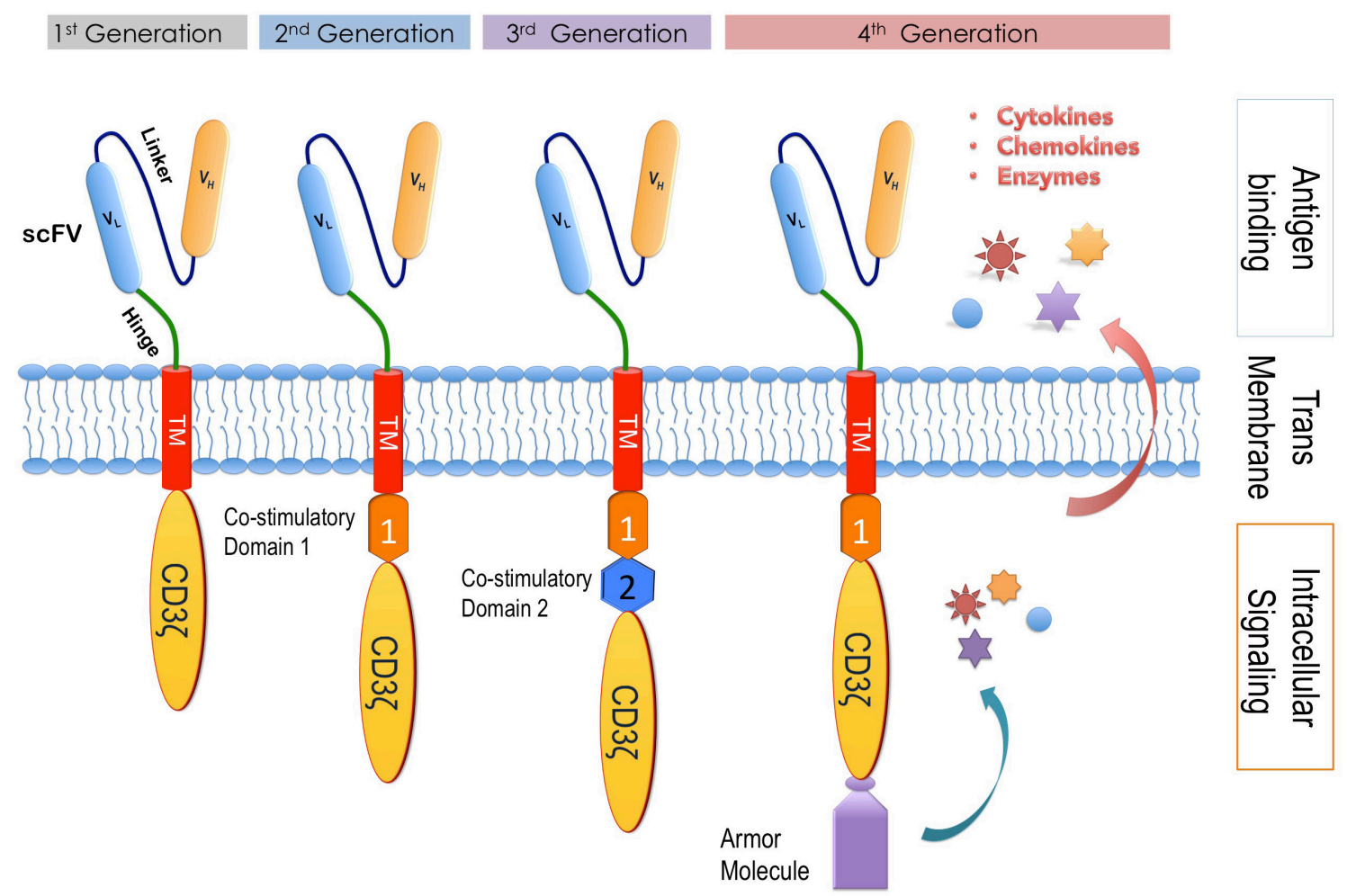

Figure 2. The evolution of CAR. The figure illustrates the different designs of CAR with the addition of various functional modules.

tumor cell model, preclinical results demonstrated that CD28/4-1BB combination outperformed the CD28/OX40 combination in terms of several CAR-T cell properties such as $\mathrm{T}$ cell persistence, basal $\mathrm{T}$ cell activation and alleviation of $\mathrm{T}$ cell exhaustion (26).

Of note, the precise molecular mechanism of CARmediated tumor killing has not been well elucidated. The anti-cancer capability may be mediated by direct tumor cytolysis and cytokine secretion. Interestingly, CD4+ CAR-T cells possess the comparable cytolytic ability with CD8+ CAR-T cells. Cytokines like TNF $\alpha$ and IFN $\gamma$ produced by CAR-T cells may contribute to the damage of tumor microenvironment and growth arrest of tumor cells $(10,11)$.

On the basis of the third generation, new design of CAR-T focuses on the addition of other co-expressed molecules as "armors" that serve various purposes: i) enhance the cytotoxic potential and leukocyte trafficking ability to target site, ii) prolong the cell survival in the suppressive environment, iii) put CAR-T cells under specific control. They are classified as the fourth generation (Figure 2). There could be diverse combinations of different "armors" in the final design for the optimal clinical result in particular cancer types. For instance, the CAR-T cells against mesothelin were engineered to co-express cytokine interleukin (IL)-7 and chemokine CCL19 on the backbone of the third generation design, which could significantly enhance the T cell proliferation and survival in solid tumor animal model (27).

\section{The application of CAR-T in blood cancer Clinical study summary}

CAR-T targeting CD19 was the paradigm for the design of CAR-T and achieved remarkable success in B cell leukemia and lymphoma. Based on the robust clinical results, FDA has approved two products. Many CAR-T therapies in B cell lymphoma showed extraordinary clinical outcomes. Some examples were listed in Table $\mathbf{1 .}$

\section{The mechanism/reason for success}

The success of CD19 CAR-T could be primarily accounted by the following factors: i) the specific target chosen for B cell malignancy. CD19 is almost the perfect target which displays the broad expression at high level in B cell malignancy. The expression of CD19 is tightly restricted to $\mathrm{B}$ cell lineage. ii) The on-target off-tumor side effect is very mild. Some patients often showed profound B cell aplasia and concurrently many of them often showed complete remission of disease. The loss of B cells can be effectively managed by replacement therapy with the infusion of immunoglobulin. iii) The acceptable control of severe adverse effects like cytokine release syndrome (CRS) and brain edema even without complete understanding of the mechanism. Currently anti-IL6 antibody, JAK inhibitors and corticosteroids are used for CRS. iv) The easy penetration of CAR-T cells to the target cells and relatively friendly and simple microenvironment for blood malignancy. 
Table 1: The clinical result of CD19 CAR-T in B cell leukemia.

\begin{tabular}{ccccccc}
\hline Sponsor & CAR co-stimulatory domain & Year & Patients & ORS (\%) & Notes & Ref \\
\hline SCH & $4-1 \mathrm{BB}$ & 2016 & 36 & $91 \%$ & $91 \%$ MRD negative CR & {$[26]$} \\
\hline MSKCC & CD28 & 2014 & 44 & $84 \%$ & $\begin{array}{l}84 \% \text { CR; MRD after CAR-T treatment is } \\
\text { negatively correlated with survival }\end{array}$ & {$[27,28]$} \\
\hline NCI & CD28 & 2015 & 39 & $61 \%$ & $61 \%$ CR; a dose-escalation trial & {$[29,30]$} \\
\cline { 2 - 6 } & $4-1 \mathrm{BB}$ & 2016 & 5 & $80 \%$ & $\begin{array}{l}80 \% \text { MRD negative CR; first allogeneic } \\
\text { CAR without causing GVHD }\end{array}$ & {$[31,32]$} \\
\hline UPENN & CD28 & 2013 & 4 & $25 \%$ & First allogeneic CAR & {$[33]$} \\
\hline BCM & CD28 & 2016 & 33 & $94 \%$ & $\begin{array}{l}\text { First CAR with defined CD4+ and CD8+ } \\
\text { T-cell subsets }\end{array}$ & {$[35]$} \\
\hline FHCRC & & & $93 \%$ & $93 \%$ CR & [34] \\
\hline
\end{tabular}

BCM, Baylor College of Medicine; CAR, chimeric antigen receptor; FHCRC, Fred Hutchinson Cancer Research Center; ORS, objective responses; MRD, minimal residual disease; MSKCC, Memorial Sloan-Kettering Cancer Center; NCI, National Cancer Institute; SCH, Seattle Children's Hospital; UPENN, University of Pennsylvania.

\section{Challenge in B cell leukemia}

Some form of resistance of CD19 CAR-T has emerged in B cell leukemia under treatment. The loss of CD19 antigen epitope appears to be the primary mechanism of tumor escape in acute leukemia. This is also the common observation for TCR-based cell therapy which depends on the efficient presentation of tumor antigen peptide on the surface of APCs by the MHC complex. About $28 \%$ of the patients in a trial with young adults and pediatric patients with acute leukemia were reported to lose the expression of CD19 epitope (35). The potential solution to this problem is to develop dual targeting CAR-T against CD19 and CD22 which are also restricted to B cell lineage (38).

Whereas in patients with chronic lymphocytic leukemia, the resistance to CAR-T therapy was largely due to the insufficient proliferation of CAR-T cells (39). The lack of persistence of CAR-T cells could be solved by better understanding the stimulatory signaling domains (40) or using different type of $\mathrm{T}$ cells like sorted memory $\mathrm{T}$ cells or stem cells (41). Another challenge is the development of idiotypic antibody against murine $\mathrm{scFv}$ region, which could be solved by the use of humanized scFv (42).

The mechanism of and the relationship between CRS and cerebral edema are still elusive. Brain edema could be the consequence of CRS and the extreme manifestation of CRS in neurological system, or totally independent process. It is speculated to be related to inflammatory cytokines. Further study in proper animal model is warranted to elucidate the details.

\section{Expansion of CAR-T beyond B cells and challenge in solid tumors}

The success of CAR-T in B cell leukemia has inspired the application into other cancers including melanoma, synovial sarcoma, prostate cancer, colon cancer, kidney cancer and lung cancer (43). However, there are some lessons learned from the CAR-T experiments in solid tumors, which remain as challenges to solve.

\section{Tumor recognition}

The crucial issue is the specificity of target molecule. This determines the cross-reactivity toxicity of $\mathrm{T}$ cells, either on-target or off-target. It is challenging to find an ideal target antigen on solid tumors. As a restriction of CAR-T therapy, the target must be on the cell surface. Very often the tumor associated antigen (TAA) is enriched on tumor surface, but it is also expressed at low level on normal tissues. So far, this problem is seen on the targets tested in clinical trials like carcinoembryonic antigen (CEA), melanoma antigen (MAGE-A3), folate receptor 1, ganglioside 2 (GD2), human epidermal growth factor receptor 2 (ERBB2), mesothelin, intracellular adhesion molecule 1 (ICAM-1), carbonic anhydrase IX (CAIX), prostate stem cell antigen (PSMA) and mucin 1 (MUC1) (44). The tiny amount of TAA expressed on normal tissues could cause catastrophic consequence in patients with CAR-T treatment (45-48). The higher affinity of CAR to the target is not necessarily correlated with the better efficacy, although the binding affinity is related to safety. The in vivo study with CAR-T against ICAM-1 demonstrated that lower affinity CAR showed better safety and efficacy with enhanced proliferation and less exhaustion when compared to the higher affinity CAR-T cells $(49,50)$. There are new developments with system engineering concept to create more sophisticated recognition circuits. For example, in addition to the single TAA targeting strategy, dual targeting CAR-T cells are also under testing. They have two receptors which constitute the AND-gate, NOT-gate and OR-gate circuits: the function of CAR-T cells is specifically determined by the combination of different targets. The general strategy is to construct two separate CARs against two targets, respectively, and one receptor bears the $\mathrm{CD} 3 \zeta$ chain and the other receptor harbors the co-stimulatory domains $(51,52)$. The upgrade version for AND-gate recognition involves the two receptors in a setting that activation of the first receptor will turn on the expression of the second receptor 
that is responsible for cytotoxic function $(53,54)$. The NOT-gate design usually incorporates the signaling motif of inhibitory molecules like PD-1 receptor into the cytoplasmic tail of the CAR which recognizes the antigen expressed on normal tissues. This inhibitory CAR will override the activation CAR which targets TAA (55). In a similar manner, the OR-gate CARs involve two different receptors recognizing two TAAs to refine the targeting and reduce tumor escape, such as CD19/CD22 or CD19/CD20 dual targeting CAR-T cells for B cell leukemia. The clinical result suggested these CAR-T cells were less sensitive to the resistance due to CD19 loss in patients $(56,57)$. These novel designs greatly improve the ability of CAR-T cells to specifically recognize tumor cells yet reduce the collateral damage on normal tissue. The progress of neo-antigen research has found a new treasure of TAA pools which will be the focus of future development of MHC-restricted CAR/TCR design. Recently, a CAR/TCR chimera design targeting the intracellular antigen NY-ESO-1 with the help of HLA-A2 showed promising result (58).

To better handle the potential on-target off-tumor side effect of CAR-T cells, researchers have developed the suicide gene cassette into CAR-T design (59). Inducible caspase 9 could trigger apoptosis when the core fragment of caspase 9 fused to FK506 binding protein (FKBP12) is activated by dimerization induced by FK506 small compound analogue AP1903 (60,61). Another control measure is to co-express the truncated epidermal growth factor receptor (EGFR) without intracellular domain in the CAR-T cells which can be eliminated by EGFR antibody cetuximab-mediated antibody-dependent cellular cytotoxicity (62). In case of unexpected severe adverse event, CAR-T cells could be removed in a controllable manner by these suicide gene designs.

To treat solid tumors effectively, CAR-T cells need to conquer the other challenges: how to find and penetrate into tumor tissues, how to survive and proliferate in the suppressive environment. Next, we will discuss the solutions to tackle the above problems.

\section{Trafficking}

$\mathrm{T}$ cells need to first move to the site of tumor. This is generally not a big issue for blood malignancies, however, it will take considerable effort for CAR-T cells to do so in solid tumors which are generally more fibrotic and not easy to penetrate. Given the important role of chemokine signaling in leukocyte trafficking, CAR-T cells were engineered to co-express chemokines or chemokine receptors, such as CCR2 and CCL19, to enhance the homing and migration ability of T cells. A case of mesothelin CAR with CCR2 expression showed more than 12-fold increase of $\mathrm{T}$ cell trafficking and tumor regression in subcutaneous malignant pleural mesotheliomas tumors. Another GD2 targeting CAR-T cells with CCR2b expression had higher than 10-fold T cell homing in neuroblastoma tumor model $(63,64)$.

Instead of systemic administration of CAR-T cells, local delivery of CAR-T cell is an alternative approach which has been tested in pre-clinical studies with some promising results. In a mouse xenograft study, a breast cancer model with brain metastasis was established, when the CAR-T cells targeting HER2 were injected to tumor intracranially, the tumor was eradicated completely and $100 \%$ survival of animals was observed even with rechallenge of tumor cells (65). Another study demonstrated that local administration of HER2-BB $\zeta$ CAR-T cells eliminated cancer with much lower dose compared to intravenous delivery (66).

\section{Survive in tumor microenvironment}

Many solid tumors are notorious for the suppressive microenvironment which comprises of inhibitory small molecules, suppressive stromal cells and immune cells. Due to the defect in vascular system, tumor cells prefer glycolytic metabolism and further render the environment hypoxic, acidic, oxidative and nutrient deprived. Inhibitory molecules like PD-1 and Galectin-9 are upregulated in the inflammatory environment and bind to the receptor on $\mathrm{T}$ cells and suppress their function. In addition to the combinatory therapy with the checkpoint antibodies which have been the most popular and successful strategy to prevent $\mathrm{T}$ cell exhaustion/inhibition, new CAR-T cells with expression of checkpoint inhibitor antibodies have shown promising results in preclinical studies. For example, anti-CAIX CAR-T cells with secretion ability of anti-PD-1 antibody showed substantially enhanced activity against tumor cells compared to normal CAR-T cells, in terms of increased cytokine secretion and immune cell recruitment in human clear cell renal carcinoma mouse model (67). Similar results were observed on CD19 CAR-T with anti-PD-1 antibody in CD19+ lung cancer xenograft model (68).

The tumor cells and their associated stromal and immune cells secrete soluble factors like TGF $\beta$, vascular endothelial growth factor, adenosine, lactate, reactive oxygen species (ROS), prostaglandin E2 and soluble Fas ligand, which contribute to the inflammation related polarization of tumor associated macrophages, abnormal tumor vasculature and suppression of $\mathrm{T}$ cell immune responses (69-71). One strategy for CAR-T design is to incorporate the antagonizing enzyme or neutralizing receptor onto cell surface. For instance, a type of CAR-T cells was engineered with catalase, the enzyme for hydrogen peroxide hydrolysis, and showed reduced oxidative stress and improved proliferation and cytotoxicity against tumor cells, compared to the original CAR without catalase (72). TGF $\beta$ has been reported to downregulate the secretion of critical Th1 cytokine like IFN $\gamma$ and impair the cytolytic function of T cells (73). To alleviate the suppressive role of TGF $\beta$, a dominant negative receptor of TGF $\beta$ RII was co-expressed in $T$ cells targeting EBV, and promoted the persistence and proliferation of such $\mathrm{T}$ cells which showed expected result in EBV positive cancers like lymphoma and nasopharyngeal carcinoma (74). Recently, a fusion protein of PD-L1 antibody and TGFßRII truncate was engineered to express on the surface of CAR-T cells and enabled the 
dual resistance to both $\mathrm{PD}-\mathrm{L} 1$ and TGF $\beta$ inhibitory signaling (75). To cope with the hypoxic environment of tumors, a CAR was engineered with oxygen-sensing domain of hypoxia-inducible factor (HIF) $1 \alpha$ which is the critical transcription factor stabilized in hypoxia. In this way the CAR will be regulated by HIF1 $\alpha$ to express at very low level in normal oxygen level, but it will be highly induced in hypoxia condition (76).

As discussed in previous section, the co-stimulatory domains of different factors are evaluated in CARs. The combination of different co-stimulatory domains plays an important and distinct role to promote $\mathrm{T}$ cell activation and persistence in tumor microenvironment. Many studies have suggested that $4-1 \mathrm{BB}$ is superior to CD28 in terms of promoting differentiation and persistence. Mechanistically, 4-1BB signaling could reprogram the metabolism of $\mathrm{T}$ cells to greater level of fatty acid oxidation and mitochondria generation than CD28, which preferentially turns on the glycolysis pathway $(11,77)$. In addition, the co-expression of cytokines and receptors vital for $\mathrm{T}$ cell proliferation is another effective approach. The cytokines include IL-4, IL-7, IL-15, IL-12 and IL-18 (78-80). A CAR targeting prostate stem cell antigen was engineered with a chimera cytokine receptor composed of the extracellular domain of IL-4 receptor and the intracellular domain of
IL-7. This kind of cells showed enhanced proliferation and good anti-tumor ability against pancreatic cancer (81).

\section{The new direction of CAR}

The CRISPR (Clustered Regularly Interspaced Short Palindromic Repeats) technology has been the most exciting progress in biotechnology. Coincidentally it was listed as the runner-up of the Top Ten Advances of the Year 2013 in Science journal in which the champion is immunotherapy for cancer. Simply put, CRISPR can be combined with CAR-T therapy to make possible the following innovative design: i) precise editing of $\mathrm{T}$ cells to remove the inhibitory signaling receptor like PD-1 pathway $(82,83)$; ii) precise insertion of CAR construct into specific locus of genome, such as TCR promoter region (84); iii) using CRISPR or other genome editing tool to knockout HLA and TCR to generate the off-theshelf CAR-T for universal application (85-87).

The application of CAR-T therapy has expanded beyond cancer, recently CD19 CAR-T is also tested in autoimmune diseases like systemic lupus erythematosus, as B cells play an essential role in the pathogenesis (88). CAR targeting myelin oligodendrocyte glycoprotein was also tested in multiple sclerosis model. More of this topic is reviewed in this article (4). CAR-T engineered with

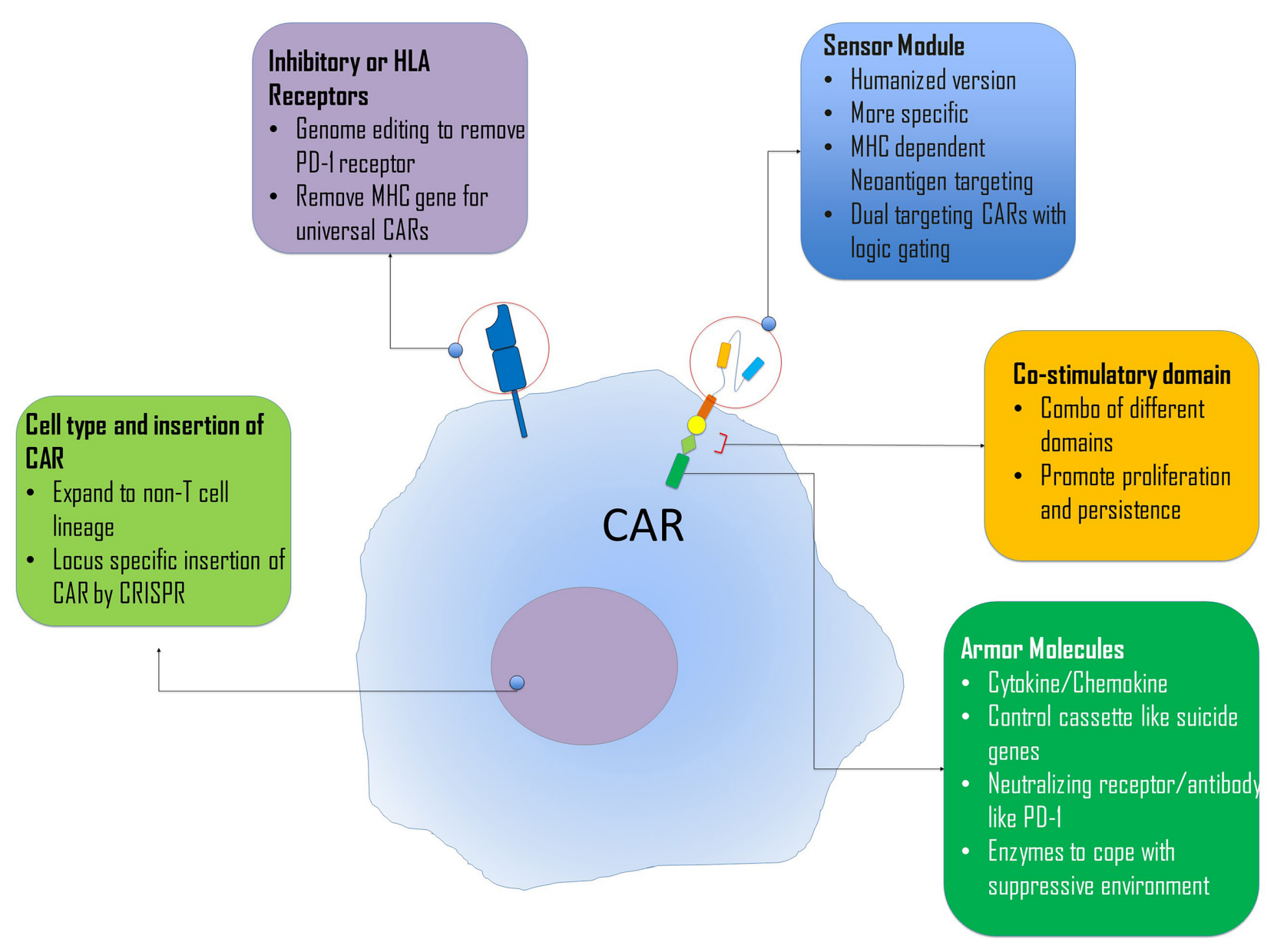

Figure 3. The summary of CAR design listing the current focus of various CAR designs. 
broadly effective neutralizing antibody also showed enhanced elimination of HIV-infected cells (89).

\section{Conclusion}

As the continuation of the concept of adoptive cell therapy, CAR-T technology has been the ensemble of the magic bullet dream for cancer therapy (Figure 3). It represents the future generation of medicine as a living platform integrated with sophisticated system biology and engineering modules with expandability, flexibility and remarkable controllability $(6,90)$. Recent success in treating acute lymphoblastic leukemia when conventional treatments failed to deliver continues to inspire the academics and the public (3). Combination of CAR with latest immunotherapy knowledge and cutting-edge genome editing tools will make cancer a chronic disease in the near future. And this technology can also apply to cell lineages other than T cells (91) and it will be the hope for other lingering threats for human health like autoimmune and infectious diseases.

\section{Conflict of interest}

The authors declare that they have no conflict of interest.

\section{References}

1. Ferlay J, Soerjomataram I, Dikshit R, Eser S, Mathers C Rebelo $\mathrm{M}$, et al. Cancer incidence and mortality worldwide: sources, methods and major patterns in GLOBOCAN 2012. Int J Cancer 2015;136:E359-86.

2. Couzin-Frankel J. Breakthrough of the year 2013. Cancer immunotherapy. Science 2013;342:1432-3.

3. M Y. No cancer cells detected: first major step to recovery for British boy in Singapore for experimental treatment. Channel News Asia 2020 Jan 16.

4. Maldini CR, Ellis GI, Riley JL. CAR T cells for infection, autoimmunity and allotransplantation. Nat Rev Immunol 2018;18:605-16.

5. Seimetz D, Heller K, Richter J. Approval of first CARTs: have we solved all hurdles for ATMPs? Cell Med 2019;11:2155179018822781.

6. Fischbach MA, Bluestone JA, Lim WA. Cell-based therapeutics: the next pillar of medicine. Sci Transl Med 2013;5:179ps7.

7. Brubaker SW, Bonham KS, Zanoni I, Kagan JC. Innate immune pattern recognition: a cell biological perspective. Annu Rev Immunol 2015;33:257-90.

8. Cooper MD, Alder MN. The evolution of adaptive immune systems. Cell 2006;124:815-22.

9. Germain RN, Stefanova I. The dynamics of T cell receptor signaling: complex orchestration and the key roles of tempo and cooperation. Annu Rev Immunol 1999;17:467-522.

10. Chen L, Flies DB. Molecular mechanisms of $T$ cell costimulation and co-inhibition. Nat Rev Immunol 2013;13:227-42.

11. van der Stegen SJ, Hamieh M, Sadelain M. The pharmacology of second-generation chimeric antigen receptors. Nat Rev Drug Discov 2015;14:499-509.

12. Burugu $S$, Dancsok AR, Nielsen TO. Emerging targets in cancer immunotherapy. Semin Cancer Biol 2018;52:39-52.

13. Mosmann TR, Cherwinski H, Bond MW, Giedlin MA, Coffman RL. Two types of murine helper $\mathrm{T}$ cell clone. I. Definition according to profiles of lymphokine activities and secreted proteins. J Immunol 1986;136:2348-57.

14. Steinman $L$. A brief history of $T(H) 17$, the first major revision in the $T(H) 1 / T(H) 2$ hypothesis of $T$ cell-mediated tissue damage. Nat Med 2007;13:139-45.

15. Chatila TA. Role of regulatory $T$ cells in human diseases. $J$ Allergy Clin Immunol 2005;116:949-59; quiz 60.

16. Dustin $\mathrm{ML}$. The cellular context of $\mathrm{T}$ cell signaling. Immunity 2009;30:482-92.

17. Valent P, Groner B, Schumacher U, Superti-Furga G, Busslinger M, Kralovics R, et al. Paul Ehrlich (18541915) and his contributions to the foundation and birth of translational medicine. J Innate Immun 2016;8:111-20.

18. Rosenberg SA, Packard BS, Aebersold PM, Solomon D, Topalian SL, Toy ST, et al. Use of tumor-infiltrating lymphocytes and interleukin-2 in the immunotherapy of patients with metastatic melanoma. A preliminary report. $\mathrm{N}$ Engl J Med 1988;319:1676-80.

19. Rosenberg SA, Restifo NP, Yang JC, Morgan RA, Dudley ME. Adoptive cell transfer: a clinical path to effective cancer immunotherapy. Nat Rev Cancer 2008;8:299-308.

20. Levine BL, Bernstein WB, Aronson NE, Schlienger K, Cotte J, Perfetto S, et al. Adoptive transfer of costimulated CD4+ T cells induces expansion of peripheral T cells and decreased CCR5 expression in HIV infection. Nat Med 2002;8:47-53.

21. Riddell SR, Watanabe KS, Goodrich JM, Li CR, Agha ME, Greenberg PD. Restoration of viral immunity in immunodeficient humans by the adoptive transfer of $\mathrm{T}$ cell clones. Science 1992;257:238-41.

22. Gross G, Waks T, Eshhar Z. Expression of immunoglobulinT-cell receptor chimeric molecules as functional receptors with antibody-type specificity. Proc Natl Acad Sci U S A 1989;86:10024-8.

23. Kuwana $\mathrm{Y}$, Asakura $\mathrm{Y}$, Utsunomiya N, Nakanishi M, Arata $\mathrm{Y}$, Itoh $\mathrm{S}$, et al. Expression of chimeric receptor composed of immunoglobulin-derived $\mathrm{V}$ regions and T-cell receptorderived $\mathrm{C}$ regions. Biochem Biophys Res Commun 1987;149:960-8.

24. Irving BA, Weiss $A$. The cytoplasmic domain of the $\mathrm{T}$ cell receptor zeta chain is sufficient to couple to receptor-associated signal transduction pathways. Cell 1991;64:891-901.

25. Drent E, Poels R, Ruiter R, van de Donk N, Zweegman S, Yuan $\mathrm{H}$, et al. Combined CD28 and 4-1BB costimulation potentiates affinity-tuned chimeric antigen receptorengineered T cells. Clin Cancer Res 2019;25:4014-25.

26. Quintarelli C, Orlando D, Boffa I, Guercio M, Polito VA, Petretto A, et al. Choice of costimulatory domains and of cytokines determines CAR T-cell activity in neuroblastoma. Oncoimmunology 2018;7:e1433518.

27. Adachi K, Kano Y, Nagai T, Okuyama N, Sakoda Y, Tamada K. IL-7 and CCL19 expression in CAR-T cells improves immune cell infiltration and CAR-T cell survival in the tumor. Nat Biotechnol 2018;36:346-51.

28. Gardner RA, Finney O, Smithers H, Leger K, Annesley CE, Summers C, et al. Prolonged functional persistence of CD19 CAR $t$ cell products of defined CD4:CD8 composition and transgene expression determines durability of MRD-negative ALL remission. J Clin Oncol 2016;34:3048.

29. Davila ML, Riviere I, Wang X, Bartido S, Park J, Curran K, et al. Efficacy and toxicity management of 19-28z CAR T cell therapy in B cell acute lymphoblastic leukemia. Sci Transl Med 2014;6:224ra25.

30. Brentjens RJ, Davila ML, Riviere I, Park J, Wang X, Cowell LG, et al. CD19-targeted T cells rapidly induce molecular remissions in adults with chemotherapy-refractory acute lymphoblastic leukemia. Sci Transl Med 2013;5:177ra38.

31. Lee DW, Gardner R, Porter DL, Louis CU, Ahmed N, Jensen $\mathrm{M}$, et al. Current concepts in the diagnosis and management of cytokine release syndrome. Blood 2014;124:188-95.

32. Lee DW, Kochenderfer JN, Stetler-Stevenson M, Cui YK, Delbrook C, Feldman SA, et al. T cells expressing CD19 chimeric antigen receptors for acute lymphoblastic leukaemia in children and young adults: a phase 1 doseescalation trial. Lancet 2015;385:517-28. 
33. Brudno JN, Kochenderfer JN. Toxicities of chimeric antigen receptor $\mathrm{T}$ cells: recognition and management. Blood 2016;127:3321-30.

34. Brudno JN, Somerville RP, Shi V, Rose JJ, Halverson DC Fowler DH, et al. Allogeneic $\mathrm{T}$ cells that express an antiCD19 chimeric antigen receptor induce remissions of B-cell malignancies that progress after allogeneic hematopoietic stem-cell transplantation without causing graft-versus-host disease. J Clin Oncol 2016;34:1112-21.

35. Maude SL, Frey N, Shaw PA, Aplenc R, Barrett DM, Bunin $\mathrm{NJ}$, et al. Chimeric antigen receptor $\mathrm{T}$ cells for sustained remissions in leukemia. N Engl J Med 2014;371:1507-17.

36. Cruz CR, Micklethwaite KP, Savoldo B, Ramos CA, Lam $\mathrm{S}, \mathrm{Ku} \mathrm{S}$, et al. Infusion of donor-derived CD19-redirected virus-specific $T$ cells for B-cell malignancies relapsed after allogeneic stem cell transplant: a phase 1 study. Blood 2013:122:2965-73.

37. Turtle CJ, Hanafi LA, Berger C, Gooley TA, Cherian S, Hudecek M, et al. CD19 CAR-T cells of defined CD4+:CD8+ composition in adult B cell ALL patients. J Clin Invest 2016;126:2123-38.

38. Fry TJ, Shah NN, Orentas RJ, Stetler-Stevenson M, Yuan CM, Ramakrishna S, et al. CD22-targeted CAR T cells induce remission in B-ALL that is naive or resistant to CD19targeted CAR immunotherapy. Nat Med 2018;24:20-8.

39. Porter DL, Hwang WT, Frey NV, Lacey SF, Shaw PA, Loren $\mathrm{AW}$, et al. Chimeric antigen receptor $\mathrm{T}$ cells persist and induce sustained remissions in relapsed refractory chronic lymphocytic leukemia. Sci Transl Med 2015;7:303ra139.

40. Milone MC, Fish JD, Carpenito C, Carroll RG, Binder GK, Teachey D, et al. Chimeric receptors containing CD137 signal transduction domains mediate enhanced survival of $\mathrm{T}$ cells and increased antileukemic efficacy in vivo. Mol Ther 2009;17:1453-64

41. Postow MA, Sidlow R, Hellmann MD. Immune-related adverse events associated with immune checkpoint blockade. N Engl J Med 2018;378:158-68.

42. Sommermeyer D, Hill T, Shamah SM, Salter AI, Chen Y, Mohler KM, et al. Fully human CD19-specific chimeric antigen receptors for T-cell therapy. Leukemia 2017;31:2191-9.

43. Li J, Li W, Huang K, Zhang Y, Kupfer G, Zhao Q. Chimeric antigen receptor $T$ cell (CAR-T) immunotherapy for solid tumors: lessons learned and strategies for moving forward. J Hematol Oncol 2018;11:22.

44. Martinez M, Moon EK. CAR T cells for solid tumors: new strategies for finding, infiltrating, and surviving in the tumor microenvironment. Front Immunol 2019;10:128.

45. Morgan RA, Yang JC, Kitano M, Dudley ME, Laurencot CM, Rosenberg SA. Case report of a serious adverse event following the administration of $T$ cells transduced with a chimeric antigen receptor recognizing ERBB2. Mol Ther 2010;18:843-51.

46. Richman SA, Nunez-Cruz S, Moghimi B, Li LZ, Gershenson ZT, Mourelatos Z, et al. High-affinity GD2-specific CAR T cells induce fatal encephalitis in a preclinical neuroblastoma model. Cancer Immunol Res 2018;6:36-46.

47. Chinnasamy N, Wargo JA, Yu Z, Rao M, Frankel TL, Riley JP, et al. A TCR targeting the HLA-A*0201-restricted epitope of MAGE-A3 recognizes multiple epitopes of the MAGE-A antigen superfamily in several types of cancer. J Immunol 2011;186:685-96

48. Morgan RA, Chinnasamy N, Abate-Daga D, Gros A, Robbins $P F$, Zheng $Z$, et al. Cancer regression and neurological toxicity following anti-MAGE-A3 TCR gene therapy. J Immunother 2013;36:133-51.

49. Min IM, Shevlin E, Vedvyas Y, Zaman M, Wyrwas B, Scognamiglio $\mathrm{T}$, et al. CAR T therapy targeting ICAM-1 eliminates advanced human thyroid tumors. Clin Cancer Res 2017;23:7569-83.

50. Park S, Shevlin E, Vedvyas Y, Zaman M, Park S, Hsu YS, et al. Micromolar affinity CAR T cells to ICAM-1 achieves rapid tumor elimination while avoiding systemic toxicity. Sci Rep 2017:7:14366.

51. Kloss CC, Condomines M, Cartellieri M, Bachmann $M$, Sadelain M. Combinatorial antigen recognition with balanced signaling promotes selective tumor eradication by engineered T cells. Nat Biotechnol 2013;31:71-5.

52. Lanitis E, Poussin M, Klattenhoff AW, Song D, Sandaltzopoulos $\mathrm{R}$, June $\mathrm{CH}$, et al. Chimeric antigen receptor $\mathrm{T}$ Cells with dissociated signaling domains exhibit focused antitumor activity with reduced potential for toxicity in vivo. Cancer Immunol Res 2013;1:43-53.

53. Morsut L, Roybal KT, Xiong X, Gordley RM, Coyle SM, Thomson $\mathrm{M}$, et al. Engineering customized cell sensing and response behaviors using synthetic Notch receptors. Cell 2016;164:780-91.

54. Roybal KT, Rupp LJ, Morsut L, Walker WJ, McNally KA, Park JS, et al. Precision tumor recognition by $T$ cells with combinatorial antigen-sensing circuits. Cell 2016;164:770-9.

55. Fedorov VD, Themeli M, Sadelain M. PD-1- and CTLA4-based inhibitory chimeric antigen receptors (iCARs) divert off-target immunotherapy responses. Sci Transl Med 2013;5:215ra172.

56. Grada Z, Hegde M, Byrd T, Shaffer DR, Ghazi A, Brawley VS, et al. TanCAR: a novel bispecific chimeric antigen receptor for cancer immunotherapy. Mol Ther Nucleic Acids 2013;2:e105

57. Zah E, Lin MY, Silva-Benedict A, Jensen MC, Chen YY. T cells expressing CD19/CD20 bispecific chimeric antigen receptors prevent antigen escape by malignant $B$ cells. Cancer Immunol Res 2016;4:498-508.

58. Patel K, Olivares S, Singh H, Hurton LV, Huls MH, Qazilbash $\mathrm{MH}$, et al. Combination immunotherapy with NY-ESO1-specific CAR<sup $>+</$ sup $>\mathrm{T}$ cells with T-cell vaccine improves anti-myeloma effect. Blood 2016;128:3366.

59. Jones BS, Lamb LS, Goldman F, Di Stasi A. Improving the safety of cell therapy products by suicide gene transfer. Front Pharmacol 2014;5:254.

60. Straathof KC, Pule MA, Yotnda P, Dotti G, Vanin EF, Brenner MK, et al. An inducible caspase 9 safety switch for T-cell therapy. Blood 2005;105:4247-54.

61. Di Stasi A, Tey SK, Dotti G, Fujita Y, Kennedy-Nasser A, Martinez C, et al. Inducible apoptosis as a safety switch for adoptive cell therapy. N Engl J Med 2011;365:1673-83.

62. Wang X, Chang WC, Wong CW, Colcher D, Sherman $\mathrm{M}$, Ostberg JR, et al. A transgene-encoded cell surface polypeptide for selection, in vivo tracking, and ablation of engineered cells. Blood 2011;118:1255-63.

63. Craddock JA, Lu A, Bear A, Pule M, Brenner MK, Rooney $\mathrm{CM}$, et al. Enhanced tumor trafficking of GD2 chimeric antigen receptor $\mathrm{T}$ cells by expression of the chemokine receptor CCR2b. J Immunother 2010;33:780-8.

64. Moon EK, Carpenito C, Sun J, Wang LC, Kapoor V, Predina $J$, et al. Expression of a functional CCR2 receptor enhances tumor localization and tumor eradication by retargeted human $\mathrm{T}$ cells expressing a mesothelin-specific chimeric antibody receptor. Clin Cancer Res 2011;17:4719-30.

65. Priceman SJ, Tilakawardane D, Jeang B, Aguilar B, Murad JP, Park AK, et al. Regional delivery of chimeric antigen receptor-engineered $\mathrm{T}$ cells effectively targets HER2(+) breast cancer metastasis to the brain. Clin Cancer Res 2018;24:95-105

66. Nellan A, Rota C, Majzner R, Lester-McCully CM, Griesinger AM, Mulcahy Levy JM, et al. Durable regression of Medulloblastoma after regional and intravenous delivery of anti-HER2 chimeric antigen receptor T cells. J Immunother Cancer 2018;6:30.

67. Suarez ER, Chang de K, Sun J, Sui J, Freeman GJ, Signoretti $S$, et al. Chimeric antigen receptor $T$ cells secreting anti-PD-L1 antibodies more effectively regress renal cell carcinoma in a humanized mouse model. Oncotarget 2016;7:34341-55. 
68. Li S, Siriwon N, Zhang X, Yang S, Jin T, He F, et al. Enhanced cancer immunotherapy by chimeric antigen receptor-modified $T$ cells engineered to secrete checkpoint inhibitors. Clin Cancer Res 2017;23:6982-92.

69. Morrot A, da Fonseca LM, Salustiano EJ, Gentile LB, Conde L, Filardy AA, et al. Metabolic symbiosis and immunomodulation: how tumor cell-derived lactate may disturb innate and adaptive immune responses. Front Oncol 2018;8:81.

70. Ohta A. A Metabolic Immune checkpoint: adenosine in tumor microenvironment. Front Immunol 2016;7:109.

71. Poggi A, Varesano S, Zocchi MR. How to hit mesenchyma stromal cells and make the tumor microenvironment immunostimulant rather than immunosuppressive. Front Immunol 2018;9:262.

72. Ligtenberg MA, Mougiakakos D, Mukhopadhyay M, Witt K, Lladser A, Chmielewski M, et al. Coexpressed catalase protects chimeric antigen receptor-redirected $\mathrm{T}$ cells as well as bystander cells from oxidative stress-induced loss of antitumor activity. J Immunol 2016;196:759-66.

73. Lohr J, Ratliff T, Huppertz A, Ge Y, Dictus C, Ahmadi R, et al. Effector T-cell infiltration positively impacts survival of glioblastoma patients and is impaired by tumor-derived TGFbeta. Clin Cancer Res 2011;17:4296-308.

74. Bollard CM, Tripic T, Cruz CR, Dotti G, Gottschalk S, Torrano V, et al. Tumor-specific T-cells engineered to overcome tumor immune evasion induce clinical responses in patients with relapsed Hodgkin lymphoma. J Clin Oncol 2018;36:1128-39.

75. Grenga I, Donahue RN, Gargulak ML, Lepone LM, Roselli $M$, Bilusic $M$, et al. Anti-PD-L1/TGFbetaR2 (M7824) fusion protein induces immunogenic modulation of human urothelial carcinoma cell lines, rendering them more susceptible to immune-mediated recognition and lysis. Urol Oncol 2018;36:93.e1-.e11

76. Juillerat $A$, Marechal A, Filhol JM, Valogne $Y$, Valton J, Duclert A, et al. An oxygen sensitive self-decision making engineered CAR T-cell. Sci Rep 2017;7:39833.

77. Kawalekar OU, O'Connor RS, Fraietta JA, Guo L, McGettigan SE, Posey AD, Jr., et al. Distinct signaling of coreceptors regulates specific metabolism pathways and impacts memory development in CAR T cells. Immunity 2016;44:380-90.

78. Gargett T, Brown MP. Different cytokine and stimulation conditions influence the expansion and immune phenotype of third-generation chimeric antigen receptor $T$ cells specific for tumor antigen GD2. Cytotherapy 2015;17:487-95.

79. Hoyos V, Savoldo B, Quintarelli C, Mahendravada A, Zhang $\mathrm{M}$, Vera J, et al. Engineering CD19-specific T Iymphocytes with interleukin-15 and a suicide gene to enhance their anti-lymphoma/leukemia effects and safety. Leukemia 2010;24:1160-70.

80. Zhang L, Morgan RA, Beane JD, Zheng Z, Dudley ME, Kassim SH, et al. Tumor-infiltrating lymphocytes genetically engineered with an inducible gene encoding interleukin-12 for the immunotherapy of metastatic melanoma. Clin Cancer Res 2015;21:2278-88.

81. Mohammed S, Sukumaran S, Bajgain P, Watanabe $\mathrm{N}$, Heslop HE, Rooney $\mathrm{CM}$, et al. Improving chimeric antigen receptor-modified $\mathrm{T}$ cell function by reversing the immunosuppressive tumor microenvironment of pancreatic cancer. Mol Ther 2017;25:249-58.

82. Ren J, Liu X, Fang $\mathrm{C}$, Jiang $\mathrm{S}$, June $\mathrm{CH}$, Zhao Y. Multiplex Genome Editing to Generate Universal CAR T Cells Resistant to PD1 Inhibition. Clin Cancer Res 2017;23:225566

83. Schumann K, Lin S, Boyer E, Simeonov DR, Subramaniam M, Gate RE, et al. Generation of knock-in primary human T cells using Cas9 ribonucleoproteins. Proc Natl Acad Sci U S A 2015;112:10437-42.

84. Eyquem J, Mansilla-Soto J, Giavridis T, van der Stegen SJ, Hamieh M, Cunanan KM, et al. Targeting a CAR to the TRAC locus with CRISPR/Cas9 enhances tumour rejection. Nature 2017;543:113-7.

85. Ren J, Zhang X, Liu X, Fang C, Jiang S, June $\mathrm{CH}$, et al. A versatile system for rapid multiplex genome-edited CAR T cell generation. Oncotarget 2017;8:17002-11.

86. Ruella M, Kenderian SS. Next-generation chimeric antigen receptor T-cell therapy: going off the shelf. BioDrugs 2017;31:473-81

87. Torikai H, Reik A, Soldner F, Warren EH, Yuen C, Zhou $Y$, et al. Toward eliminating HLA class I expression to generate universal cells from allogeneic donors. Blood 2013;122:1341-9.

88. Kansal R, Richardson N, Neeli I, Khawaja S, Chamberlain D, Ghani M, et al. Sustained B cell depletion by CD19-targeted CAR T cells is a highly effective treatment for murine lupus. Sci Transl Med 2019;1.1.

89. Ali A, Kitchen SG, Chen ISY, Ng HL, Zack JA, Yang OO HIV-1-Specific Chimeric Antigen Receptors Based on Broadly Neutralizing Antibodies. J Virol 2016;90:6999-7006

90. Lim WA, June $\mathrm{CH}$. The principles of engineering immune cells to treat cancer. Cell 2017;168:724-40.

91. Patel S, Burga RA, Powell AB, Chorvinsky EA, Hoq N, McCormack SE, et al. Beyond CAR T cells: other cell-based immunotherapeutic strategies against cancer. Front Oncol 2019;9:196. 